\title{
Predictors of In-Hospital Mortality in Korean Patients with Acute Myocardial Infarction
}

\author{
Hae Young Yang ${ }^{1}$, Min Joo Ahn ${ }^{1}$, Myung Ho Jeong ${ }^{1, *}$, Youngkeun Ahn ${ }^{1}$, Young Jo Kim ${ }^{2}$, \\ Myeong Chan Cho ${ }^{3}$, Chong Jin Kim ${ }^{4}$, and other Korea Acute Myocardial Infarction Registry \\ Investigators \\ ${ }^{1}$ Department of Cardiology, Chonnam National University Hospital, Gwangju, ${ }^{2}$ Yeungnam University Hospital, Daegu, ${ }^{3}$ Chungbuk \\ National University Hospital, Cheongju, ${ }^{4}$ Kyunghee University Hospital, Seoul, Korea
}

Acute myocardial infarction (AMI) is a fatal cardiovascular disease, and mortality is relatively high; therefore, integrated assessment is necessary for its management. There are several risk predictive models, but treatment trends have changed due to newly introduced medications and the universal use of percutaneous coronary intervention (PCI). The author aimed to find out predictive factors of in-hospital mortality in Korean patients with AMI. A group of 13,104 patients with AMI enrolled in the Korea Acute Myocardial Infarction Registry-National Institute of Health (KAMIR-NIH) registry were divided into two groups. One was a derivation group for evaluating mortality prediction; the other was a validation group for the application of risk prediction. In-hospital mortality was $4.2 \%(\mathrm{n}=552)$. With hierarchical and stepwise multivariate analyses, nine factors were shown to predict in-hospital mortality for Korean patients with AMI. These were 1) being over 65 years of age, 2) high Killip class over II, 3) hyperglycemia over $180 \mathrm{mg} / \mathrm{dl}, 4)$ tachycardia over $100 / \mathrm{min}, 5)$ serum creatinine over 1.5 $\mathrm{mg} / \mathrm{dl}, 6$ ) atypical chest pain, 7) low systolic blood pressure under $90 \mathrm{mmHg}, 8$ ) low Thrombolysis In Myocardial Infarction (TIMI) flow (TIMI 0-II) before PCI and 9) low TIMI flow (TIMI 0-II) after PCI. The validation group showed a predictive power of 88.3\%. Old age, high Killip class, hyperglycemia, tachycardia, renal dysfunction, atypical chest pain, low systolic blood pressure, and low TIMI flow are important risk factors of in-hospital mortality in Korean patients with AMI.

Key Words: Myocardial Infarction; Risk Factors; Prognosis

This is an Open Access article distributed under the terms of the Creative Commons Attribution Non-Commercial License (http://creativecommons.org/licenses/by-nc/4.0) which permits unrestricted non-commercial use, distribution, and reproduction in any medium, provided the original work is properly cited.

\section{Article History:}

Received September 17, 2018

Revised November 27, 2018

Accepted December 4, 2018

\author{
Corresponding Author: \\ Myung Ho Jeong \\ Department of Cardiology, \\ Chonnam National University Hospital, \\ 42 Jebong-ro, Dong-gu, Gwangju \\ 61469, Korea \\ Tel: +82-62-220-6243 \\ Fax: +82-62-228-7174 \\ E-mail: myungho@chollian.net
}

\section{INTRODUCTION}

Cardiovascular disease is the most common cause of death globally and the second most common cause of death in Korea. ${ }^{1}$ Although there are on-going efforts to improve outcomes, such as prevention and new medical and interventional methods, high in-hospital mortality is still reported in patients with acute myocardial infarction (AMI). ${ }^{2}$ From admission to discharge, a continuous risk assessment and stratification are important for effective treatment and early intervention. There are several risk models for AMI, ${ }^{3-5}$ but there is limited data for predicting in-hospital mortality for Korean patients with AMI in the era of in- vasive strategies. The recent Korean AMI registry data also shows differences compared with Western registries including the incidence of AMI, character of dyslipidemia, and interventional strategy. ${ }^{6}$

The current trend of AMI in Korea shows that increasingly, patients are treated with percutaneous coronary intervention (PCI). ${ }^{2}$ Therefore, taking angiographic parameters into consideration is important in Korean patients. The previously published discharge scoring system of Korean AMI patients only took into account whether the patient underwent PCI or not. ${ }^{7}$ The authors evaluated not only the implementation status of PCI but also coronary angiographic findings as a prognostic factor. 
In this study, the authors investigated current predictive factors for in-hospital mortality of Korean patients with AMI focusing on angiographic findings.

\section{MATERIALS AND METHODS}

\section{Study population}

From November 2011 to October 2015, a total of 13,104 patients $(9,686$ male, age $64.0 \pm 12.6)$ with AMI were enrolled in the Korea Acute Myocardial Infarction-National Institute of Health (KAMIR-NIH) registry. The KAMIR$\mathrm{NIH}$ registry is a multicenter, prospective registry for Korean AMI patients. ${ }^{8}$ Participants include 20 tertiary university hospitals performing PCI and coronary artery bypass graft (CABG) surgery. This registry was approved by the institutional review board of each participating hospital, and informed consent was obtained from all patients. The authors divided the patients into two groups randomly by using a statistics program. One was the derivation group $(60 \%)$ and the other was the validation group (40\%). The asymmetric ratio was chosen to increase the power for derivation group. Given the numbers, it was thought the validation group would still be sufficiently large.

\section{Definition}

AMI was diagnosed based on increased cardiac enzymes, including cardiac troponin, with at least one value above the 99th percentile of the upper normal range accompanied by at least one of the following: symptoms of myocardial ischemia, EKG changes (ST-segment elevation in more than two continuous leads: $0.2 \mathrm{mV}$ elevation in V1 to V3, $0.1 \mathrm{mV}$ elevation in the other lead except V1 to V3), new left bundle branch block, or ST change without ST elevation (horizontal or downslope ST depression over $0.05 \mathrm{mV}$ in more than two contiguous leads, $\mathrm{T}$ wave inversion in more than two leads), and imaging studies suggesting myocardial infarction (loss of viable myocardium or new regional wall motion abnormality). Atypical chest pain was defined as inappropriate characteristics of chest pain for typical angina. For example, chest pain not aggravated by exertion, but aggravated by coughing or movement, with tenderness or if its nature was stabbing. Coronary blood flow was classified by the Thrombolysis in Myocardial Infarction (TIMI) grade. Death from any cause during admission was considered in-hospital mortality.

\section{Statistical analysis}

All the statistical processes were done using $R$ version 3.4.1. Continuous variables are described as means \pm standard deviations. Discrete variables are described as counts and percentages. The authors divided the population into two groups using random sampling. To avoid different sampling whenever we performed these seperations, the authors used the function 'set.seed', n=nrow(yhy) 'trainIndex=sample(1:n, size=round $\left(0.6^{*} \mathrm{n}\right)$,replace=FALSE)' in $\mathrm{R}$ program. To analyze predictive factors for in-hospital mortality, univariate and multivariate analyses (a combi- nation of hierarchical and stepwise methods), and logistic regressions were done. A Receiver Operating Curve was used to validate the mortality predicting power of factors. All variables were considered significant at the level of $\mathrm{p}<0.05$.

\section{RESULTS}

\section{Baseline clinical characteristics}

A total of 13,104 patients with AMI were included in this study. During hospitalization, all-cause death occurred in 552 patients $(4.2 \%)$. The mean age of the patients was $64.0 \pm 12.6$ years and male patients were $74 \%(9,686)$. Mean body weight was $65.3 \pm 12 \mathrm{~kg}$. The systolic and diastolic blood pressures were $130.4 \pm 30.3 \mathrm{~mm} / \mathrm{Hg}$ and $78.7 \pm 18.5$ $\mathrm{mm} / \mathrm{Hg}$ respectively, and the heart rate was $78.7 \pm 19.3$ beats/minute. Most of the patients (86\%) complained of typical chest pain. Killip class was classified as I (77.9\%), II (9\%), III (7.4\%) and IV (5.6\%). Risk factors were current smoking (38\%), hypertension (51\%), diabetes mellitus (29\%), and dyslipidemia (11\%). Previously diagnosed myocardial infarction was $7.6 \%$, and $6.4 \%$ had a family history of coronary artery disease (Table 1).

\section{Laboratory and echocardiographic findings}

Laboratory findings showed serum hemoglobin of $13.75 \pm$ $2.15 \mathrm{~g} / \mathrm{dl}$, serum glucose of $171.0 \pm 84.0 \mathrm{mg} / \mathrm{dl}$, total cholesterol of $177.8 \pm 46.2 \mathrm{mg} / \mathrm{dl}$, triglycerides of $135 \pm 129 \mathrm{mg} / \mathrm{dl}$, high density lipoprotein-cholesterol of $42.8 \pm 12.5 \mathrm{mg} / \mathrm{dl}$, low density lipoprotein cholesterol of $111.9 \pm 40.4 \mathrm{mg} / \mathrm{dl}$, high sensitivity C-reactive protein of $1.51 \pm 5.67 \mathrm{mg} / \mathrm{dl}$, creatine kinase of $1.13 \pm 1.17 \mathrm{U} / \mathrm{L}$, and a creatine kinase-myocardial band isoenzyme of $110 \pm 176 \mathrm{ng} / \mathrm{dl}$ (Table 1). Echocardiographic findings showed a left ventricular ejection fraction (LVEF) of $51.91 \pm 10.97 \%$. The percentage of patients with LVEF under $40 \%$ was $12.3 \%$ ( $\mathrm{n}=964)$.

\section{Coronary angiographic findings and procedural characteristics}

The number of left main coronary arterial lesions was $574(4.4 \%)$, left anterior descending coronary arterial lesions was 9,574 (73\%), left circumflex coronary arterial lesions was 5,202 (40\%), and right coronary arterial lesions was 7,635 (58\%). About 44\% (3,484) of the patients had multivessel disease. The American College of Cardiology/ American Heart Association's classification of coronary artery lesions was $101(0.013 \%)$ for type A and 7,761 (98.7\%) for non-type A. TIMI flow before PCI was as follows: 3,311 (50\%) for TIMI 0, 744 (10\%) for TIMI I, 1,123 (20\%) for TIMI II, and 1,865 (30\%) for TIMI III. TIMI flow after PCI was as follows: $28(0.4 \%)$ for TIMI 0, $33(0.4 \%)$ for TIMI I, $201(2.5 \%)$ for TIMI II, and 6,781 (86.3\%) for TIMI III (Table 2).

\section{Medications during hospitalization}

Treatment medications taken after AMI were aspirin (99.4\%), clopidogrel (78\%), prasugrel (11.8\%), ticagrelor $(31 \%)$, beta-blocker $(80 \%)$, calcium channel blocker $(8 \%)$, 
TABLE 1. Baseline clinical characteristics and laboratory findings

\begin{tabular}{|c|c|c|c|}
\hline & $\begin{array}{l}\text { Derivation group } \\
(\mathrm{n}=7862,60 \%)\end{array}$ & $\begin{array}{l}\text { Validation group } \\
(\mathrm{n}=5242,40 \%)\end{array}$ & $\begin{array}{c}\text { Total } \\
(\mathrm{n}=13104)\end{array}$ \\
\hline Age (years) & $64.0 \pm 12.6$ & $63.9 \pm 12.7$ & $64.0 \pm 12.6$ \\
\hline Men, n (\%) & $5792(74 \%)$ & $3894(74 \%)$ & $9686(74 \%)$ \\
\hline Chest pain (Typical), n (\%) & $6788(86 \%)$ & $4507(86 \%)$ & $11295(86 \%)$ \\
\hline Systolic BP (mmHg) & $130.4 \pm 30.3$ & $129.8 \pm 29.9$ & $130.1 \pm 30.1$ \\
\hline Heart rate $(/ \mathrm{min})$ & $78.7 \pm 19.3$ & $78.5 \pm 20.0$ & $78.7 \pm 19.6$ \\
\hline \multicolumn{4}{|l|}{ Killip class } \\
\hline $\mathrm{I}, \mathrm{n}(\%)$ & $6124(77.9 \%)$ & $4095(78.1 \%)$ & $10219(78 \%)$ \\
\hline II, n (\%) & $710(9 \%)$ & $422(8.1 \%)$ & $1132(8.6 \%)$ \\
\hline III, n (\%) & $584(7.4 \%)$ & $394(7.5 \%)$ & $978(7.5 \%)$ \\
\hline $\mathrm{IV}, \mathrm{n}(\%)$ & $443(5.6 \%)$ & $329(6.3 \%)$ & $772(5.9 \%)$ \\
\hline Current smoker, n (\%) & $3024(38 \%)$ & $2087(40 \%)$ & $5111(39 \%)$ \\
\hline Hypertension, $\mathrm{n}(\%)$ & $4027(51 \%)$ & $2662(50.1 \%)$ & $6689(51 \%)$ \\
\hline Diabetes mellitus, n (\%) & $2272(29 \%)$ & $1479(28 \%)$ & $3751(29 \%)$ \\
\hline Dyslipidemia, n (\%) & $903(11 \%)$ & $571(11 \%)$ & $1474(11 \%)$ \\
\hline Familial history of CAD, n (\%) & $503(6.4 \%)$ & $327(6 \%)$ & $830(6.3 \%)$ \\
\hline Previous MI, n (\%) & $597(7.6 \%)$ & $432(8 \%)$ & $1029(7.9 \%)$ \\
\hline Serum hemoglobin (g/dl) & $13.75 \pm 2.15$ & $13.79 \pm 2.14$ & $13.77 \pm 2.14$ \\
\hline Serum glucose $(\mathrm{mg} / \mathrm{dl})$ & $171.0 \pm 84.0$ & $168.5 \pm 81.1$ & $170.0 \pm 82.9$ \\
\hline Total cholesterol (mg/dl) & $177.8 \pm 46.2$ & $178.0 \pm 46.7$ & $177.9 \pm 46.4$ \\
\hline Triglyceride (mg/dl) & $135 \pm 129$ & $134.3 \pm 106.0$ & $134.5 \pm 120.1$ \\
\hline HDL-cholesterol (mg/dl) & $42.8 \pm 12.5$ & $42.8 \pm 12.6$ & $42.8 \pm 12.5$ \\
\hline LDL-cholesterol (mg/dl) & $111.9 \pm 40.4$ & $111.8 \pm 40.9$ & $111.9 \pm 40.6$ \\
\hline High-sensitivity CRP (mg/dl) & $1.51 \pm 5.67$ & $1.6 \pm 6.9$ & $1.55 \pm 6.20$ \\
\hline Serum creatinine $(\mathrm{mg} / \mathrm{dl})$ & $1.13 \pm 1.17$ & $1.14 \pm 1.24$ & $1.13 \pm 1.20$ \\
\hline Creatine kinase (U/L) & $995 \pm 1968$ & $1056 \pm 1936$ & $1019 \pm 1955$ \\
\hline CK-MB (ng/dl) & $110 \pm 176$ & $111 \pm 145$ & $111 \pm 164$ \\
\hline Troponin-I (ng/ml) & $46.46 \pm 114.89$ & $47.38 \pm 69.91$ & $46.832 \pm 105.59$ \\
\hline
\end{tabular}

Values are presented as mean \pm SD or number (percentage). BP: blood pressure, CAD: coronary artery disease, MI: myocardial infarction, HDL: high-density lipoprotein, LDL: low-density lipoprotein, CRP: C-reactive protein, CK-MB: creatine kinase-myocardial band isoenzyme.

angiotensin converting enzyme inhibitor (46\%), angiotensin II receptor blocker (31\%), and statins (90\%) (Table 3).

\section{Univariate and multivariate analyses for predictors of in-hospital mortality}

Hierarchical and stepwise methods (backward elimination) were applied. The univariate and multivariate analysis showed that the following were important risk factors for predicting in-hospital mortality (Table 4): 1) being older than 65 (HR 2.4715 95\% CI 1.8686-3.2690, p<0.001), 2) high Killip class (HR 4.4534 85\% CI 3.3854-5.8585, $\mathrm{p}<0.001$ ), 3) admission hyperglycemia $\geq 180 \mathrm{mg} / \mathrm{dl}$ (HR 2.4386 95\% CI 1.9039-3.1235, $<<0.001)$, 4) tachycardia (heart rate $>100 / \mathrm{min}$ ) (HR 1.9999 95\% CI 1.5307-2.6129), 5) renal dysfunction (creatinine $>1.5 \mathrm{mg} / \mathrm{dl}$ ) (HR $2.241795 \%$ CI 1.7248-2.9135, $\mathrm{p}<0.001), 6$ ) atypical chest pain (HR 1.6732 95\% CI 1.2839-2.1807, $\mathrm{p}<0.01)$, 7) low systolic blood pressure (<90 mmHg) (HR 2.4392 95\% CI 1.7603-3.3798, $\mathrm{p}<0.001), 8$ ) coronary angiographic TIMI blood flow before percutaneous coronary intervention (PCI) (HR 2.4104 95\% CI 1.6828-3.4526, $\mathrm{p}<0.01)$ and 9$)$ after PCI $(\mathrm{p}<0.001)(\mathrm{HR}$ $4.268295 \%$ CI 2.7947-6.5186, $\mathrm{p}<0.001$ ) (Table 5).
Application of this model to the validation cohort showed a predictive power of $88.3 \%$ in the prediction of in-hospital mortality in patients with AMI (Fig. 1).

\section{DISCUSSION}

The aim of this study was to create a model for the prediction of in-hospital mortality of Korean patients with AMI. Nine factors were evaluated for this purpose: old age, high Killip class, hyperglycemia, tachycardia, renal dysfunction, atypical chest pain, low systolic blood pressure, and low TIMI flow before and after PCI. The predictive value of these factors on mortality was $88.3 \%$.

Cardiovascular disease is the second most common cause of death in Korea and the cause-specific death rate in the 100 thousands which gradually has increased over 10 years, from 41.1 to 58.2 during the period 2006-2016. ${ }^{1}$ The early (30-day) mortality rate due to AMI decreased from $10.5 \%$ in 1999 to $7.8 \%$ in $2008 .{ }^{9}$ The KAMIR-NIH registry dataset provides an adequate sample size for evaluation. This study divided it into two groups randomly to determine predictive factors and validate its usefulness. 
TABLE 2. Echocardiographic and coronary angiographic findings

\begin{tabular}{|c|c|c|c|}
\hline & $\begin{array}{l}\text { Derivation group } \\
(\mathrm{n}=7862,60 \%)\end{array}$ & $\begin{array}{l}\text { Validation group } \\
(\mathrm{n}=5242,40 \%)\end{array}$ & $\begin{array}{c}\text { Total } \\
(\mathrm{n}=13104)\end{array}$ \\
\hline \multicolumn{4}{|l|}{ Echocardiographic findings } \\
\hline LVEF, $\%$ & $51.91 \pm 10.97$ & $51.82 \pm 11.02$ & $52.03 \pm 10.89$ \\
\hline $\mathrm{LVEF}<40 \%, \mathrm{n}(\%)$ & $964(12.3 \%)$ & $656(12.5 \%)$ & $1620(12.4 \%)$ \\
\hline \multicolumn{4}{|c|}{ Coronary angiographic findings } \\
\hline \multicolumn{4}{|c|}{ Lesion location } \\
\hline Left main, n (\%) & $376(4.80 \%)$ & $223(4.30 \%)$ & $599(4.60 \%)$ \\
\hline $\mathrm{LAD}, \mathrm{n}(\%)$ & $9574(73.0 \%)$ & $5766(73.0 \%)$ & $3808(73.0 \%)$ \\
\hline LCX, n (\%) & $5202(40.0 \%)$ & $3120(40.0 \%)$ & $2082(40.0 \%)$ \\
\hline $\mathrm{RCA}, \mathrm{n}(\%)$ & $7635(58.0 \%)$ & $4632(59.0 \%)$ & $3003(57.0 \%)$ \\
\hline Multivessel disease, n (\%) & $3484(44.3 \%)$ & $2277(43.4 \%)$ & $5761(44.0 \%)$ \\
\hline \multicolumn{4}{|l|}{ ACC/AHA classification } \\
\hline Type A, n (\%) & $101(1.3 \%)$ & $67(1.3 \%)$ & $168(1.3 \%)$ \\
\hline Type B1, n (\%) & $882(11.2 \%)$ & $522(10.0 \%)$ & $1404(10.7 \%)$ \\
\hline Type B2, n (\%) & $2570(32.7 \%)$ & $1795(34.2 \%)$ & $4365(33.3 \%)$ \\
\hline Type C, n (\%) & $3489(44.4 \%)$ & $2325(44.4 \%)$ & $5814(44.4 \%)$ \\
\hline Balloon, n (\%) & $470(6.0 \%)$ & $330(6.3 \%)$ & $800(6.1 \%)$ \\
\hline Stent, $\mathrm{n}(\%)$ & $6525(83.0 \%)$ & $4352(83.0 \%)$ & $10877(83.0 \%)$ \\
\hline \multicolumn{4}{|l|}{ Pre-PCI TIMI flow } \\
\hline $0, \mathrm{n}(\%)$ & $3311(50 \%)$ & $2208(50 \%)$ & $5519(50 \%)$ \\
\hline $\mathrm{I}, \mathrm{n}(\%)$ & $744(10 \%)$ & $541(10 \%)$ & $1285(10 \%)$ \\
\hline $\mathrm{II}, \mathrm{n}(\%)$ & $1123(20 \%)$ & $690(10 \%)$ & $1814(20 \%)$ \\
\hline III, n (\%) & $1865(30 \%)$ & $1271(30 \%)$ & $3136(30 \%)$ \\
\hline \multicolumn{4}{|l|}{ Post-PCI TIMI flow } \\
\hline $0, \mathrm{n}(\%)$ & $28(0.4 \%)$ & $21(0.4 \%)$ & $49(0.4 \%)$ \\
\hline $\mathrm{I}, \mathrm{n}(\%)$ & $33(0.4 \%)$ & $24(0.5 \%)$ & $57(0.4 \%)$ \\
\hline II, n (\%) & $201(2.6 \%)$ & $118(2.3 \%)$ & $319(2.4 \%)$ \\
\hline III, n (\%) & $6781(86.2 \%)$ & $4547(86.7 \%)$ & $11328(86.5 \%)$ \\
\hline
\end{tabular}

Values are presented as mean \pm SD or number (percentage). LVEF: left ventricular ejection fraction, LAD: Left anterior descending coronary artery, LCX: Left circumflex coronary artery, RCA: Right coronary artery, ACC/AHA: American College of Cardiology/ American Heart Association.

TABLE 3. Medications during hospitalizations

\begin{tabular}{lccc}
\hline & $\begin{array}{c}\text { Derivation group } \\
(\mathrm{n}=7862,60 \%)\end{array}$ & $\begin{array}{c}\text { Validation group } \\
(\mathrm{n}=5242,40 \%)\end{array}$ & $\begin{array}{c}\text { Total } \\
(\mathrm{n}=13104)\end{array}$ \\
\hline Aspirin & $7811(99.4 \%)$ & $5222(99.6 \%)$ & $13033(99.5 \%)$ \\
Clopidogrel & $6119(78 \%)$ & $4141(79 \%)$ & $10360(78 \%)$ \\
Prasugrel & $930(11.8 \%)$ & $632(12.1 \%)$ & $1562(11.9 \%)$ \\
Ticagrelor & $1766(30.1 \%)$ & $1133(30 \%)$ & $2899(31 \%)$ \\
Beta-blocker & $6328(80 \%)$ & $4265(80 \%)$ & $10593(81 \%)$ \\
Calcium & $642(8 \%)$ & $435(8 \%)$ & $1077(8 \%)$ \\
channel & & & \\
blocker & & & $6022(46 \%)$ \\
ACE & $3590(46 \%)$ & $2432(46 \%)$ & \\
inhibitor & & & $4096(31 \%)$ \\
Angiotensin & $2444(31 \%)$ & $1652(31 \%)$ & \\
receptor & & & $11839(90 \%)$ \\
blocker & & &
\end{tabular}

$\Rightarrow$ Values are presented as number (percentage). ACE: angiotensin-converting enzyme.

Elderly patients with ischemic heart disease had more complicated coronary lesions and a higher proportion of un- stable angina, worse LV function, and more comorbidity; as a result, more complications occurred after reperfusion therapy such as PCI or CABG. ${ }^{10,11}$ The authors defined old age as being over 65 years and assessed this as a risk. Old age was a significant and powerful predictive factor of in-hospital mortality.

The Killip classification is a prognostic factor derived from blood pressure and auscultation, and its relationship to in-hospital mortality is reported. ${ }^{12}$ Killip class is a very powerful predictive factor of in-hospital mortality in this study, similar to the findings reported elsewhere. ${ }^{5}$

Hyperglycemia at admission is associated with myocardial necrosis and in-hospital mortality in patients with or without diabetes. ${ }^{13,14}$ Higher mortality was observed in non-diabetic patients with hyperglycemia compared to diabetic patients in Korea. ${ }^{15}$

Heart rate was obtained during admission initial vital signs and, is a component of risk scoring systems for AMI and associated with 30-day in-hospital mortality. ${ }^{16}$ Tachycardia increases myocardial oxygen demand and aggravates myocardial ischemia.

The cardiovascular disease risk is high in patients with chronic kidney disease (CKD), and it is the most common 
TABLE 4. Univariate analysis for predictors of in-hospital mortality

\begin{tabular}{|c|c|c|c|}
\hline & Beta coefficient & $\mathrm{p}$ value & $\mathrm{HR}(95 \% \mathrm{CI})$ \\
\hline Age $>65$ years & 1.314 & $<0.001$ & $3.723(2.864-4.838)$ \\
\hline Men & -0.576 & $<0.001$ & $0.562(0.448-0.705)$ \\
\hline Chest pain (Typical) & -1.375 & $<0.001$ & $0.250(0.200-0.320)$ \\
\hline Systolic BP (mmHg) & -0.027 & $<0.001$ & $0.970(0.970-0.980)$ \\
\hline Diastolic BP (mmHg) & -0.040 & $<0.001$ & $0.960(0.960-0.970)$ \\
\hline Heart rate $(/ \mathrm{min})$ & 0.022 & $<0.001$ & $1.022(1.017-1.027)$ \\
\hline \multicolumn{4}{|l|}{ Killip class } \\
\hline II & 1.405 & $<0.001$ & $4.077(2.803-5.921)$ \\
\hline III & 2.129 & $<0.001$ & $8.404(6.062-11.651)$ \\
\hline IV & 3.326 & $<0.001$ & $27.823(20.850-37.126)$ \\
\hline Current smoker & -0.699 & $<0.001$ & $0.497(0.418-0.591)$ \\
\hline Hypertension & 0.257 & $<0.05$ & $1.293(1.036-1.613)$ \\
\hline Diabetes mellitus & 0.532 & $<0.001$ & $1.702(1.361-2.130)$ \\
\hline Dyslipidemia & -0.586 & $<0.01$ & $0.557(0.362-0.855)$ \\
\hline Familial history of CAD & -0.934 & $<0.01$ & $0.393(0.201-0.767)$ \\
\hline Previous myocardial infarction & 0.109 & 0.59 & $1.115(0.750-1.660)$ \\
\hline Serum hemoglobin (g/dl) & -0.312 & $<0.001$ & $0.730(0.700-0.770)$ \\
\hline Serum glucose $(\mathrm{mg} / \mathrm{dl})$ & 0.006 & $<0.001$ & $1.006(1.010-1.007)$ \\
\hline Total cholesterol (mg/dl) & -0.010 & $<0.001$ & $0.990(0.990-0.990)$ \\
\hline Triglyceride (mg/dl) & -0.001 & $<0.001$ & $0.999(0.997-1.000)$ \\
\hline HDL-cholesterol (mg/dl) & -0.039 & $<0.001$ & $0.960(1.950-0.970)$ \\
\hline LDL-cholesterol (mg/dl) & -0.007 & $<0.001$ & $0.993(0.989-1.000)$ \\
\hline High-sensitivity CRP (mg/dl) & 0.030 & $<0.001$ & $1.030(1.015-1.046)$ \\
\hline Creatine kinase (U/L) & 0.000 & $<0.001$ & $1.000(1.000-1.000)$ \\
\hline CK-MB (ng/dl) & 0.001 & $<0.001$ & $1.001(1.000-1.001)$ \\
\hline Left main disease & 1.172 & $<0.001$ & $5.542(3.9708-7.7351)$ \\
\hline Multivessel disease & 0.35391 & $<0.001$ & $1.425(1.1198-1.8125)$ \\
\hline ACC/AHA classification type A & -0.797 & $<0.270$ & $0.451(0.11-1.83)$ \\
\hline \multicolumn{4}{|l|}{ Pre-PCI TIMI } \\
\hline I & -0.2004 & 0.34 & $0.818(0.542-1.235)$ \\
\hline II & -0.2576 & 0.16 & $0.773(0.542-1.103)$ \\
\hline III & -0.8053 & $<0.001$ & $0.447(0.313-0.639)$ \\
\hline \multicolumn{4}{|l|}{ Post-PCI TIMI } \\
\hline I & -0.258 & 0.629 & $0.772(0.271-2.205)$ \\
\hline II & -1.516 & $<0.001$ & $0.220(0.092-0.522)$ \\
\hline III & -3.003 & $<0.001$ & $0.050(0.023-0.107)$ \\
\hline
\end{tabular}

BP: blood pressure, CAD: coronary artery disease, HDL: high-density lipoprotein, LDL: low-density lipoprotein, CRP: C-reactive protein, CK-MB: creatine kinase-myocardial band isoenzyme, ACC/AHA: American College of Cardiology/American Heart Association.

TABLE 5. Multivariate analysis for predictors of in-hospital mortality

\begin{tabular}{lccc}
\hline & Beta coefficient & p value & HR (95\% CI) \\
\hline Age $>$ 65 years & 0.9048 & $<0.001$ & $2.4715(1.8686-3.2690)$ \\
Chest pain (Atypical) & 0.5148 & $<0.01$ & $1.6732(1.2839-2.1807)$ \\
Systolic BP $<90 \mathrm{mmHg}$ & 0.8917 & $<0.001$ & $2.4392(1.7603-3.3798)$ \\
Heart rate $>100 / \mathrm{min}$ & 0.6931 & $<0.001$ & $1.9999(1.5307-2.6129)$ \\
Killip class II-V & 1.4937 & $<0.001$ & $4.4534(3.3854-5.8585)$ \\
Serum glucose $>180 \mathrm{mg} / \mathrm{dl}$ & 0.8914 & $<0.001$ & $2.4386(1.9039-3.1235)$ \\
Serum creatinine $>1.5 \mathrm{mg} / \mathrm{dl}$ & 0.8072 & $<0.001$ & $2.2417(1.7248-2.9135)$ \\
Low Pre-PCI TIMI (0-II) & 0.8798 & $<0.01$ & $2.4104(1.6828-3.4526)$ \\
Low Post-PCI TIMI (0-II) & 1.4512 & $<0.001$ & $4.2682(2.7947-6.5186)$ \\
\hline
\end{tabular}

BP: blood pressure, pre-PCI TIMI: TIMI blood flow before PCI, post-PCI TIMI: TIMI blood flow after PCI. 


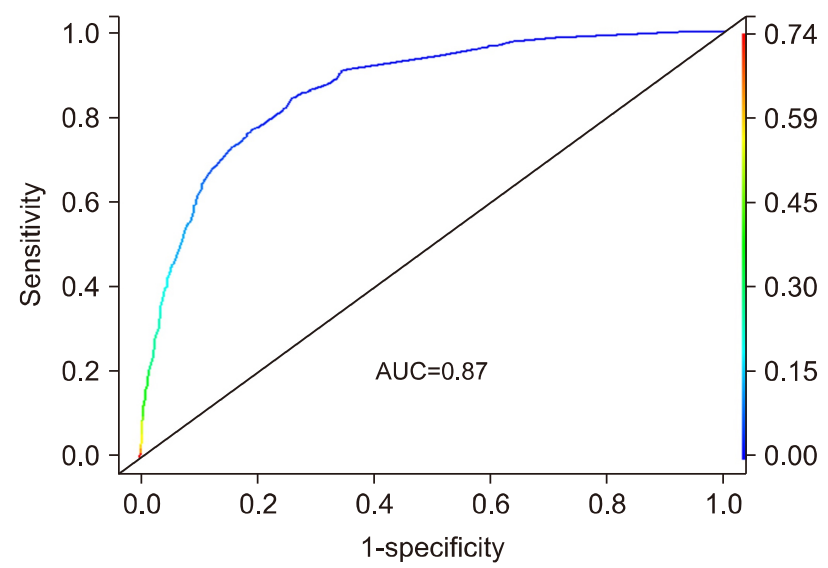

FIG. 1. The receiver operating characteristic (ROC) curve using the predictive model. It shows area under curve of 0.87. AUC: area under the curve.

cause of death in end-stage renal disease (ESRD). ${ }^{17,18}$ The fatal or non-fatal MI incidence and mortality of MI increased as stages of CKD increased. A level of serum creatinine higher than $1.5 \mathrm{mg} / \mathrm{dl}$ is an important risk factor in in-hospital mortality.

Unrecognized AMI or AMI without chest pain is more frequently observed in patients with diabetes and hypertension, ${ }^{19}$ but little data exists about the symptoms of AMI and in-hospital outcomes. A recent study shows that atypical symptoms of AMI reduced invasive treatment and induced poor outcomes. ${ }^{20}$ Early detection and active treatment of this patient group is, therefore, an important goal. Atypical or asymptomatic patients with AMI are at high risk for in-hospital mortality.

TIMI flow before and after PCI is also an important factor. To the best of our knowledge, no previous studies have described whether pre-PCI TIMI flow is an independent prognostic factor. This study suggests that pre-PCI TIMI flow, considered separately from post-PCI TIMI flow, is also an important prognostic factor.

The TIMI risk score was developed in 2000 for acute coronary syndrome, and the global registry of acute coronary event (GRACE) risk model was developed in 2006..$^{3-5}$ Korean patients show different features compared with patients from Western countries including risk factors, dyslipidemia profiles, and response to medical treatment. ${ }^{6}$ In this context the KAMIR hospital discharge score (KAMIR score) for Korean patients was developed in 2011 and compared with the GRACE risk scoring system. The KAMIR score consisted of six independent risk factors for one-year major adverse cardiac events and showed a better predictive power and was easier to calculate than the GRACE score. The KAMIR score included age, Killip class, serum creatinine, in-hospital PCI, left ventricular ejection fraction, and admission glucose. It showed that renal function and in-hospital PCI were important prognostic factors for Korean patients. However, treatment trends have changed and are ever-evolving. Most patients in Korea now have in-hospital PCI due to geographic accessibility to a PCI cen- ter and access to national health insurance. Therefore, TIMI flow before and after PCI may be a meaningful prognostic factor for Korean patients.

A three year clinical follow-up of the KAMIR-NIH registry will be completed in 2019 . This registry may provide valuable information about important long-term prognostic factors in recent Korean patients with myocardial infarction. A new KAMIR-NIH score predicting the in-hospital and long-term mortality will thus be available in the future.

In conclusion, this study analyzed 13,104 AMI patients enrolled in the KAMIR-NIH registry and divided the patients into two groups to evaluate risk factors associated with in-hospital mortality and validated its predictive power. Through hierarchical and stepwise multivariate analyses, it showed that old age, high Killip class, hyperglycemia, tachycardia, renal dysfunction, atypical chest pain, low systolic blood pressure, and coronary angiographic TIMI flow before and after PCI are important risk factors predicting in-hospital mortality in Korean patients with AMI.

Most of these factors are included in the existing scoring systems, such as the GRACE score and TIMI score. However, coronary angiographic TIMI flow before and after PCI are also important risk factors predicting in-hospital mortality in Korean patients with AMI. Therefore, a new scoring system for Korean AMI patients which includes the coronary angiographic TIMI flow before and after PCI should be considered.

\section{Study limitations}

First, in-hospital mortality for Korean patients with AMI could be an underestimation. The hospitals participating in the KAMIR-NIH registry are leading hospitals of Korea where early invasive strategies are more widely applied than at other locations, so a selection bias could be argued. More nationwide registry data could decrease this problem. Second, despite their strong predictive power, the degree of contribution of these risk factors to death was not considered in this model, so a new risk scoring system needs to be developed. Furthermore, validation with other AMI cohorts will be necessary.

\section{ACKNOWLEDGEMENTS}

The authors thank all of the clinical investigators who contributed time and effort to this study, as well as the Korea Acute Myocardial Infarction (KAMIR-NIH) Investigators.

\section{CONFLICT OF INTEREST STATEMENT}

None declared.

\section{REFERENCES}

1. Statis Korea. Causes of death in Korea [Internet]. Dajeon: Statistics Korea; c2018 [cited 2018 Aug 1]. Available from: 
http://www.korea.kr/news/pressReleaseView.do?newsId= $156227504 /$.

2. Kook HY, Jeong MH, Oh S, Yoo SH, Kim EJ, Ahn Y, et al. Current trend of acute myocardial infarction in Korea (from the Korea Acute Myocardial Infarction Registry from 2006 to 2013). Am J Cardiol 2014;114:1817-22.

3. Antman EM, Cohen M, Bernink PJ, McCabe CH, Horacek T, Papuchis G, et al. The TIMI risk score for unstable angina/non-ST elevation MI: a method for prognostication and therapeutic decision making. JAMA 2000;284:835-42.

4. Morrow DA, Antman EM, Parsons L, de Lemos JA, Cannon CP, Giugliano RP, et al. Application of the TIMI risk score for ST-elevation MI in the National Registry of Myocardial Infarction 3. JAMA 2001;286:1356-9.

5. Fox KA, Dabbous OH, Goldberg RJ, Pieper KS, Eagle KA, Van de Werf F, et al. Prediction of risk of death and myocardial infarction in the six months after presentation with acute coronary syndrome: prospective multinational observational study (GRACE). BMJ 2006;333:1091.

6. Sim DS, Jeong MH. Differences in the Korea Acute Myocardial Infarction Registry compared with Western Registries. Korean Circ J 2017;47:811-22.

7. Kim HK, Jeong MH, Ahn Y, Kim JH, Chae SC, Kim YJ, et al. Hospital discharge risk score system for the assessment of clinical outcomes in patients with acute myocardial infarction (Korea Acute Myocardial Infarction Registry [KAMIR] score). Am J Cardiol 2011;107:965-71.e1.

8. Kim JH, Chae SC, Oh DJ, Kim HS, Kim YJ, Ahn Y, et al. Multicenter cohort study of acute myocardial infarction in Korea - interim analysis of the Korea Acute Myocardial Infarction Registry-National Institutes of Health Registry. Circ J 2016;80: 1427-36.

9. Yeh RW, Sidney S, Chandra M, Sorel M, Selby JV, Go AS. Population trends in the incidence and outcomes of acute myocardial infarction. N Engl J Med 2010;362:2155-65.

10. Batchelor WB, Anstrom KJ, Muhlbaier LH, Grosswald R, Weintraub WS, O'Neill WW, et al. Contemporary outcome trends in the elderly undergoing percutaneous coronary interventions: results in 7,472 octogenarians. National Cardiovascular Network Collaboration. J Am Coll Cardiol 2000;36:723-30.

11. Kobayashi Y, Mehran R, Mintz GS, Dangas G, Moussa I, Lansky
AJ, et al. Comparison of in-hospital and one-year outcomes after multiple coronary arterial stenting in patients $>$ or $=80$ years old versus those <80 years old. Am J Cardiol 2003;92:443-6.

12. Killip T 3rd, Kimball JT. Treatment of myocardial infarction in a coronary care unit. A two year experience with 250 patients. Am J Cardiol 1967;20:457-64.

13. Hao Y, Lu Q, Li T, Yang G, Hu P, Ma A. Admission hyperglycemia and adverse outcomes in diabetic and non-diabetic patients with non-ST-elevation myocardial infarction undergoing percutaneous coronary intervention. BMC Cardiovasc Disord 2017;17:6.

14. Bhadriraju S, Ray KK, DeFranco AC, Barber K, Bhadriraju P, Murphy SA, et al. Association between blood glucose and longterm mortality in patients with acute coronary syndromes in the OPUS-TIMI 16 trial. Am J Cardiol 2006;97:1573-7.

15. Kim EJ, Jeong MH, Kim JH, Ahn TH, Seung KB, Oh DJ, et al. Clinical impact of admission hyperglycemia on in-hospital mortality in acute myocardial infarction patients. Int $\mathrm{J}$ Cardiol 2017;236:9-15.

16. Wiviott SD, Morrow DA, Frederick PD, Antman EM, Braunwald E; National Registry of Myocardial Infarction. Application of the Thrombolysis in Myocardial Infarction risk index in non-ST-segment elevation myocardial infarction: evaluation of patients in the National Registry of Myocardial Infarction. J Am Coll Cardiol 2006;47:1553-8.

17. McCullough PA, Vassalotti JA, Collins AJ, Chen SC, Bakris GL. National Kidney Foundation's Kidney Early Evaluation Program (KEEP) annual data report 2009: executive summary. Am J Kidney Dis 2010;55(3 Suppl 2):S1-3.

18. Gansevoort RT, Correa-Rotter R, Hemmelgarn BR, Jafar TH, Heerspink HJ, Mann JF, et al. Chronic kidney disease and cardiovascular risk: epidemiology, mechanisms, and prevention. Lancet 2013;382:339-52.

19. Feringa $\mathrm{HH}$, Karagiannis $\mathrm{SE}$, Vidakovic R, Elhendy A, ten Cate FJ, Noordzij PG, et al. The prevalence and prognosis of unrecognized myocardial infarction and silent myocardial ischemia in patients undergoing major vascular surgery. Coron Artery Dis 2007;18:571-6.

20. Kim I, Kim MC, Park KH, Sim DS, Hong YJ, Kim JH, et al. Prognostic significance of non-chest pain symptoms in patients with non-ST-segment elevation myocardial infarction. Korean J Intern Med 2018;33:1111-8. 